\title{
PENYULUHAN HUKUM TENTANG PENTINGNYA HAK KEKAYAAN INTELEKTUAL PADA KELOMPOK TENUN TRADISIONAL "BIA BEREK" DI DESA KUNERU - ATAMBUA (NTT)
}

\author{
Valerie Selvie Sinaga ${ }^{1}$ \\ ${ }^{1}$ Fakultas Hukum, Universitas Katolik Indonesia Atma Jaya \\ Email: valerie.selvie@atmajaya.ac.id
}

\begin{abstract}
Intellectual Property Rights (IPR) is a set of rights granted to exploit an object that is the result of human thought. $I P R$ consists of various rights including copyright, trademark, patent, industrial design, and trade secrets. These rights are needed in developing a business, both large and small businesses. Legal counselling on the importance of IPR was given to the "Bia Berek" group consisting of mothers of traditional weaving craftsmen from the Kemak tribe in Kuneru village, Manumutin Urban Village, Atambua District, Belu Regency (East Nusa Tenggara (NTT)) in August 2018. As small businesses in traditional industries, an introduction to the importance of IPR for this group is given so that they can protect the object of intellectual property rights owned and utilize the IPR to advance their small businesses. After legal counselling is carried out, group members understand that their creativity in making woven fabrics is one of the assets protected by copyright and plagiarism of fabric motifs from other regions or groups is not permitted in the copyright regime. In addition, group members understand that a brand is needed to be able to market their woven fabrics more broadly. However, they are still unable to register their weaving work to obtain brand protection, industrial design, and $I G$, due to their limited funds, knowledge and access. There needs to be further assistance from the Regency Government regarding this IPR issue.
\end{abstract}

Keywords: Copyright; Trademark Rights; Weaving; Small and Medium Enterprises; Atambua - NTT

\begin{abstract}
ABSTRAK
Hak Kekayaan Intelektual (HKI) adalah serangkaian hak yang diberikan untuk mengeksploitasi suatu obyek yang merupakan hasil dari pemikiran manusia. HKI terdiri dari berbagai hak di antaranya hak cipta, merek, paten, desain industri, dan rahasia dagang. Hak-hak ini sangat dibutuhkan dalam mengembangkan suatu usaha, baik usaha besar atau pun kecil. Penyuluhan hukum akan pentingnya HKI ini diberikan kepada kelompok "Bia Berek" yang beranggotakan ibu-ibu pengrajin tenun tradisional dari suku Kemak di desa Kuneru, Kelurahan Manumutin, Kecamatan Kota Atambua, Kabupaten Belu (Nusa Tenggara Timur (NTT)) pada bulan Agustus 2018. Sebagai pelaku usaha kecil di industri tradisional, pengenalan akan arti pentingnya HKI bagi kelompok ini diberikan agar mereka dapat melindungi obyek hak kekayaan intelektual yang dimiliki dan memanfaatkan HKI tersebut untuk memajukan usaha kecil mereka. Setelah penyuluhan hukum dilakukan, anggota kelompok memahami bahwa kreatifitas mereka dalam membuat kain tenunan merupakan salah satu asset yang dilindungi oleh hak cipta dan penjiplakan motif kain tenun dari daerah atau kelompok lain merupakan hal yang tidak diperkenankan dalam rezim hak cipta. Selain itu, anggota kelompok memahami bahwa diperlukan merek untuk dapat memasarkan lebih luas lagi kain hasil tenunan mereka. Namun, mereka masih belum mampu mendaftarkan karya tenun mereka untuk mendapatkan perlindungan merek, desain industri, dan IG, karena keterbatasan dana, pengetahuan dan akses mereka. Perlu ada pendampingan lebih lanjut dari pihak Pemerintah Daerah Kabupaten terkait masalah HKI ini.
\end{abstract}

Kata kunci: Hak Cipta, Hak Merek, Tenun, Usaha Kecil Menengah, Atambua - NTT

\section{PENDAHULUAN}

Pengabdian masyarakat merupakan salah satu dari Tri Dharma Perguruan Tinggi yang wajib dilaksanakan oleh seorang dosen. Bagi dosen Fakultas Hukum, penyuluhan hukum merupakan salah satu bentuk dari pengabdian kepada masyarakat. Penyuluhan hukum yang diberikan harus sesuai dengan bidang keilmuan dari dosen yang bersangkutan. Target dari penyuluhan hukum tersebut adalah masyarakat luar lingkungan perguruan tinggi tempat bekerja dosen tersebut.

Kegiatan penyuluhan hukum kali ini berfokus pada bidang Hak Kekayaan Intelektual (HKI) yang merupakan bidang keilmuan dari penulis. HKI terdiri dari serangkaian hak yang diberikan untuk melindungi ciptaan yang dihasilkan oleh pemikiran manusia. HKI terdiri dari paten, hak cipta, merek, desain industri, desain tata letak sirkuit terpadu, rahasia dagang, dan perlindungan varietas 
tanaman. HKI sangat penting diintegrasikan sebagai suatu strategi bisnis dan apabila dikelola dengan baik dapat menguntungkan suatu usaha, baik usaha kecil, menengah (UKM) maupun usaha besar (Sinaga, 2012).

Target penyuluhan hukum ini adalah kelompok tenun ikat Bia Berek yang berasal dari Desa Kuneru, Kabupaten Belu, NTT. Kelompok ini berdiri sejak tahun 2007 dengan anggota saat ini berjumlah 20 orang ibu-ibu yang tinggal di desa tersebut. Awalnya kelompok dibentuk atas dasar swadaya dari para pendiri, salah satunya adalah Ibu Maria Goreti Bisoi, dengan diketuai oleh Ibu Viktoria Naimau dan didampingi oleh Bapak Marthen Naibuti dari Dewan Kerajinan Nasional Daerah (Dekranasda) Kabupaten Belu. (Bisoi, M.G. (2018, 4 Agustus). Wawancara Pribadi). Alasan pendirian kelompok ini adalah untuk melestarikan budaya leluhur dan memberdayakan potensi para ibu anggotanya yang memiliki ketrampilan menenun. Selain itu, kelompok ini didirikan untuk membantu para ibu memenuhi kebutuhan ekonomi keluarga dan melatih kemandirian ekonomi para ibu agar tidak lagi hanya mengharapkan penghasilan dari suami (Fallo, 2016)

Industri kain tenun yang ditekuni ibu-ibu anggota kelompok Bia Berek merupakan industri kreatif yang didasarkan dari pengetahuan budaya tradisional daerah tersebut memiliki banyak potensi yang dapat dijadikan obyek berbagai HKI, seperti hak cipta, merek, dan desain industri. Walaupun memiliki banyak potensi yang menguntungkan industri tenun tradisional Atambua, sistem HKI juga memiliki banyak persyaratan yang sulit dipenuhi oleh UKM dalam industri tenun tradisional. Artikel ini membahas penyuluhan hukum yang dilakukan oleh penulis pada kelompok tenun ikat "Bia Berek" pada tanggal 5 Agustus 2018. Pada penyuluhan hukum tersebut diketahui berbagai permasalahan yang dihadapi oleh kelompok ini terhadap isu perlindungan HKI untuk produk yang mereka hasilkan.

\section{METODE}

Metode yang dipakai dalam Penyuluhan Hukum tentang HKI ini adalah metode seminar, yaitu penulis yang bertindak sebagai penyuluh memberikan pemaparan tentang cabang-cabang HKI yang relevan memberikan manfaat bagi bagi industri tenun ikat di Atambua. Materi diberikan dengan memberikan pengetahuan dan informasi tentang HKI dan industri kreatif dengan juga memberikan contoh-contoh kasus yang ada. Setelah selesai memberikan pemaparan, penyuluh memberikan kesempatan kepada peserta untuk bertanya. Sebagai alat ukur tentang efektifitas dari penyuluhan ini, penyuluh memberikan beberapa pertanyaan lisan untuk mengetahui tingkat pengetahuan peserta tentang HKI dan industri kreatif di Indonesia sebelum dan setelah selesai penyuluhan tersebut. Penyuluhan dilakukan di rumah adat salah ketua kelompok Bia Berek di Desa Kuneru. Karena ketiadaan listrik di tempat penyuluhan, penyuluh tidak dapat memaparkan menggunakan laptop dan projector.

\section{HASIL DAN PEMBAHASAN}

\section{Cabang HKI Yang Membantu Pengembangan Industri Tenun Tradisional Atambua}

Seperti yang telah ditulis di awal artikel ini, penyuluhan hukum tentang HKI memberikan pemahaman kepada para anggota kelompok Bia Berek terdiri dari beberapa hak yang memilki kaitan erat untuk pengembangan industri tenun tradisional.

\section{a. Hak Cipta dan Ekspresi Budaya Tradisional}

Tenun ikat merupakan salah satu ciptaan yang dilindungi oleh Hak Cipta. Walaupun tidak dinyatakan secara tegas dalam batang tubuh Undang-undang No. 28/ 2014 tentang Hak Cipta (UUHC 2014), tetapi 'motif tenun ikat' disebutkan secara eksplisit dalam Penjelasan Pasal 40 
huruf $\mathrm{j}$ sebagai salah satu yang dilindungi oleh Hak Cipta. Ketentuan dalam Pasal 40 huruf j ini lebih ditujukan kepada motif tenun ikat kontemporer yang dapat diketahui siapa penciptanya. Untuk motif tenun ikat tradisional yang sudah lama diketahui, dipakai dalam tekstil suku atau etnis di Desa Kuneru, dan penciptanya tidak diketahui, karya semacam ini dikategorikan sebagai ekspresi budaya tradisional yang diatur dalam Pasal 38 UUHC 2014.

Menurut Pasal 58 (1) UUHC 2014, perlindungan hak cipta atas karya tenun ikat kontemporer yang dilindungi dalam Pasal 40 huruf $\mathrm{j}$ adalah seumur hidup si pencipta ditambah sampai 70 tahun setelah si pencipta meninggal dunia. Sedangkan, Pasal 38 (1) UUHC 2014 menyatakan, untuk tenun ikat yang termasuk kategori ekspresi budaya tradisional (EBT), pemegang hak ciptanya adalah Negara. Perlindungan untuk tenun ikat dalam kategori EBT, menurut Pasal 60 (1) UUHC 2014 diberikan selama-lamanya tanpa batas waktu.

Pasal 38 (2) UUHC 2014 mewajibkan Negara untuk menginventarisasi, menjaga dan memelihara ekspresi budaya tradisional. Selanjutnya, Pasal 38 (3) UUHC 2014 menyatakan penggunaan ekspresi budaya tradisional diharuskan untuk memperhatikan nilai-nilai yang hidup dalam masyarakat pengembannya. Menurut Pasal 38 (4) UUHC 2014, ketentuan lebih lanjut mengenai hak cipta ekspresi budaya tradisional yang dipegang oleh Negara akan diatur dengan Peraturan Pemerintah (PP).

PP yang diamanatkan oleh UUHC 2014 sama seperti ketentuan Pasal 10 (4) UUHC 2002. Namun, PP tersebut tidak pernah terealisasikan sampai dengan berakhirnya UUHC 2002 di tahun 2014. Setelah 5 tahun UUHC 2014 diundangkan, PP yang diamanatkan dalam Pasal 38 (4) tersebut juga belum dikeluarkan oleh pemerintah. PP tersebut dibutuhkan untuk memperjelas kedudukan masyarakat tradisional yang hak cipta atas ekspresi budaya tradisionalnya dipegang oleh Negara seperti diatur dalam Pasal 38 (1) UUHC 2014, terutama dalam hal pembagian hak ekonomi atas eksploitasi ekspresi budaya tradisional tersebut.

\section{b. Desain Industri}

Desain industri adalah cabang HKI lain yang memberikan perlindungan pada industri tenun ikat. Tetapi berbeda dengan hak cipta yang melindungi seni murni, hak desain industri diberikan untuk sebuah karya seni pakai. Motif-motif tenun yang diproduksi secara massal dengan metode printing di pabrik adalah obyek perlindungan desain industri yang sesuai dengan definisi desain industri pada Pasal 1 (1) UU No. 31/2000 tentang Desain Industri (UUDI 2000) yang berbunyi:

Desain Industri adalah suatu kreasi tentang bentuk, konfigurasi, atau komposisi garis atau warna, atau garis dan warna, atau gabungan daripadanya yang berbentuk tiga dimensi atau dua dimensi yang memberikan kesan estetis dan dapat diwujudkan dalam pola tiga dimensi atau dua dimensi serta dapat dipakai untuk menghasilkan suatu produk, barang, komoditas industri, atau kerajinan tangan.

Tidak seperti hak cipta yang tidak membutuhkan pendaftaran sebagai syarat perlindungan, menurut Pasal 5 (1) UUDI 2000, desain industri dilindungi melalui pendaftaran untuk 10 tahun sejak masuknya aplikasi tersebut ke Direktorat Jenderal HKI. Pasal 2 (1) UUDI 2000 mensyaratkan adanya unsur kebaruan bagi suatu karya untuk mendapat perlindungan desain industry. Persyaratan baru ini berbeda dengan persyaratan orisinal yang diminta untuk mendapat perlindungan hak cipta. Walaupun banyak desain tenun ikat yang diproduksi saat ini mengandung motif tradisional, jika pencipta menambahkan elemen baru maka karya tersebut dapat dilindungi oleh desain industri (Sinaga, 2012). 


\section{c. Rahasia Dagang}

Pengetahuan tentang teknik pembuatan dan proses pewarnaan alami tenun ikat Atambua, termasuk peralatan, seperti Alat Tenun Bukan Mesin (ATBM), adalah subjek perlindungan rahasia dagang yang sesuai dengan ketentuan Pasal 2 ayat (1) UU No. 30 Tahun 2000 tentang Rahasia Dagang (UURD 2000). Pasal 3 (4) UURD 2000 menyatakan perlindungan rahasia dagang diberikan terhadap informasi yang memiliki dinilai ekonomis dan dijaga kerahasiannya oleh pemiliknya. Tidak seperti pembuatan kain batik yang lebih popular diketahui umum, termasuk orang-orang di luar Indonesia, pembuatan tenun ikat Atambua dengan teknik pewarnaan alami masih belum banyak diketahui orang. Oleh karena itu, sangat penting bagi para anggota kelompok Bia Berek untuk menjaga informasi bernilai ekonomis ini agar keunikan tenun ikat karya mereka tidak ditiru pihak luar Atambua.

\section{d. Merek}

Setiap usaha, baik kecil atau pun besar, memerlukan merek untuk mendukung pemasaran dari produk-produknya. Merek aalah suatu tanda yang membedakan barang atau jasa milik pihak lain dalam suatu perdagangan (Saidin, 2004). Di samping itu, merek juga memberikan jaminan kualitas dari suatu barang atau jasa yang berbeda dari lainnya (Saidin, 2004). Merek memiliki arti penting bagi pemasaran suatu produk dan bila dikembangkan dengan baik, suatu merek memiliki nilai lebih tinggi dari asset suatu badan usaha (Sinaga, 2012).

Menurut Pasal 35 (1) Undang-undang Merek dan Indikasi Geografis No. 20/ 2016 (UUM 2016), perlindungan merek diberikan untuk jangka waktu 10 tahun sejak tanggal penerimaan aplikasi merek. Selanjutnya, Pasal 35 (2) UUM 2016 menyatakan perlindungan ini dapat diperpanjang untuk jangka waktu yang sama. Saat ini banyak pengrajin tenun ikat, termasuk kelompok Bia Berek, yang belum memiliki merek untuk memasarkan produknya. Hal ini dikarenakan para pengrajin tenun ikat Atambua kurang pengetahuan tentang arti pentingnya merek bagi suatu bisnis. Selain itu, seperti UKM di industri batik (Sinaga, 2014), para ibu pengrajin tenun ikat Atambua juga merasa proses pendaftaran merek rumit dan menelan biaya yang tidak sedikit (Bisoi, M.G. dan Naimau, V. (2018, 5 Agustus). Wawancara Pribadi).

\section{e. Indikasi Geografis (IG)}

IG dapat mencegah tindakan penyalahgunaan produk tenun ikat tersebut oleh pihak asing karena Pasal 22 (2a) the Trade Related Aspects of Intellectual Property Rights Agreement (TRIPS) menjamin perlindungan dari penggunaan IG yang menyesatkan publik sebagai asal geografis suatu barang. Kemudian, perlindungan IG dapat dijadikan sebagai tindakan melawan persaingan curang seperti yang dinyatakan dalam Pasal 22 (2b) TRIPS (Rangnekar, 2003). Di Indonesia, IG diatur dalam Pasal 53-62 UUM 2016. Dalam Pasal 53 UUM 2016 dinyatakan bahwa perlindungan IG diberikan kepada lembaga yang mewakili masyarakat di kawasan geografis tertentu dan pemerintah daerah provinsi atau kabupaten/ kota yang mengusahakan suatu barang dan/ atau produk berupa sumber daya alam; barang kerajinan tangan; atau hasil industri. IG dapat diberikan untuk produk tenun ikat, baik yang diproses dengan mesin atau ditenun dengan tangan. Pasal 53 (1) UUM 2016 menggariskan bahwa perlindungan IG untuk industri tenun ikat diperoleh melalui sistem pendaftaran. Yang dapat mendaftarkan IG hanyalah lembaga yang mewakili masyarakat di lokasi geografis pembuatan tenun ikat Atambua dan pemerintah daerah provinsi atau kota/kabupaten. Kelompok tenun ikat Bia Berek dapat dikategorikan sebagai lembaga yang mewakili masyarakat di lokasi geografis seperti yang disebutkan dalam Pasal 53 (2) UUM 2016. Namun, kelompok Bia Berek masih kesulitan mendaftarkan perlindungan IG di Indonesia. 


\section{Pelaksanaan Penyuluhan Hukum Pada Kelompok Tenun Ikat Bia Berek (Desa Kuneru, 5 Agustus 2019)}

Kegiatan penyuluhan hukum diikuti oleh para ibu anggota Kelompok Tenun Ikat Bia Berek yang berjumlah 20 orang dan ditambah beberapa ibu dari desa tetangga yang juga berprofesi sebagai pengrajin tenun ikat. Jumlah total peserta penyuluhan hukum adalah 30 orang. Kegiatan dimulai jam 10.00 setelah para ibu selesai mengurusi rumah tangga mereka masing-masing.

Dari pre-questions yang diajukan penyuluh dapat disimpulkan bahwa tingkat pengetahuan HKI pada peserta penyuluhan ini masih rendah. Namun kebanyakan dari mereka sudah mengetahui bahwa motif dan pengetahuan mereka dalam membuat tenun ikat merupakan sesuatu yang berharga dan perlu untuk dilindungi. Ketika penyuluh memaparkan tentang cabang-cabang HKI yang dapat membantu pengembangan usaha tenun ikat, peserta antusias bertanya dengan menampilkan berbagai kasus yang mereka pernah dengar. Contohnya, salah satu peserta bertanya tentang eksploitasi komersial motif tradisional Atambua yang dipakai oleh desainer tingkat dunia. Penyuluh menjawab bahwa seharusnya eksploitasi komersial itu juga memberikan keuntungan bagi masyarakat di wilayah motif itu berasal.

Hal ini seharusnya menjadi tanggung jawab Pemerintah Daerah Provinsi atau Kabupaten/ Kota untuk mendaftarkan motif tradisional sebagai IG daearah tersebut dan mengupayakan agar keuntungan tersebut bisa juga diberikan ke masyarakat sekitar. Setelah penyuluhan selesai, penyuluh memberikan post-questions yang dapat dijawab cukup baik oleh ibu-ibu peserta penyuluhan. Ini menunjukkan bahwa penyuluhan yang diberikan cukup efektif memberikan pengetahuan tentang pentingnya HKI kepada para ibu pengrajin tenun ikat di Desa Kuneru tersebut.

Setelah satu tahun berlalu, kelompok tenun ikat Bia Berek semakin memahami fungsi hak cipta dan ekspresi budaya tradisional, merek, desain industri, IG dan rahasia dagang untuk membantu pengembangan usaha tenun ikat mereka. Sekarang pemasaran tenun ikat karya anggota Kelompok Bia Berek dilakukan melalui media sosial, seperti Facebook, Instagram, dan Whatsapp. Walaupun sudah ada kemajuan dalam pemasaran, tetapi kelompok ini masih belum memiliki merek dan mendaftarkannya ke Dirjen HKI. Mereka beranggapan usaha mereka masih terlalu kecil untuk mengeluarkan biaya pendaftaran merek yang tidak sedikit bagi mereka. Foto kegiatan dapat dilihat pada Gambar 1 dan Gambar 2.

\section{SIMPULAN DAN SARAN}

Kegiatan penyuluhan hukum tentang HKI pada Kelompok Tenun Ikat Bia Berek sudah berjalan baik. Walaupun hasil belum dapat dirasakan langsung, tetapi setidaknya para anggota kelompok tenun ini sudah mengetahui bahwa karya tenun ikat mereka adalah sesuatu karya kreatif yang bernilai ekonomi tinggi, sehingga patut mendapat perlindungan HKI dalam cabang hak cipta/ ekspresi budaya tradisional, merek, desain industri, rahasia dagang, dan IG. Namun, mereka masih belum mampu mendaftarkan karya tenun mereka untuk mendapatkan perlindungan merek, desain industri, dan IG, karena keterbatasan dana, pengetahuan dan akses mereka. Perlu ada pendampingan lebih lanjut dari pihak Pemerintah Daerah Kabupaten terkait masalah HKI ini. 


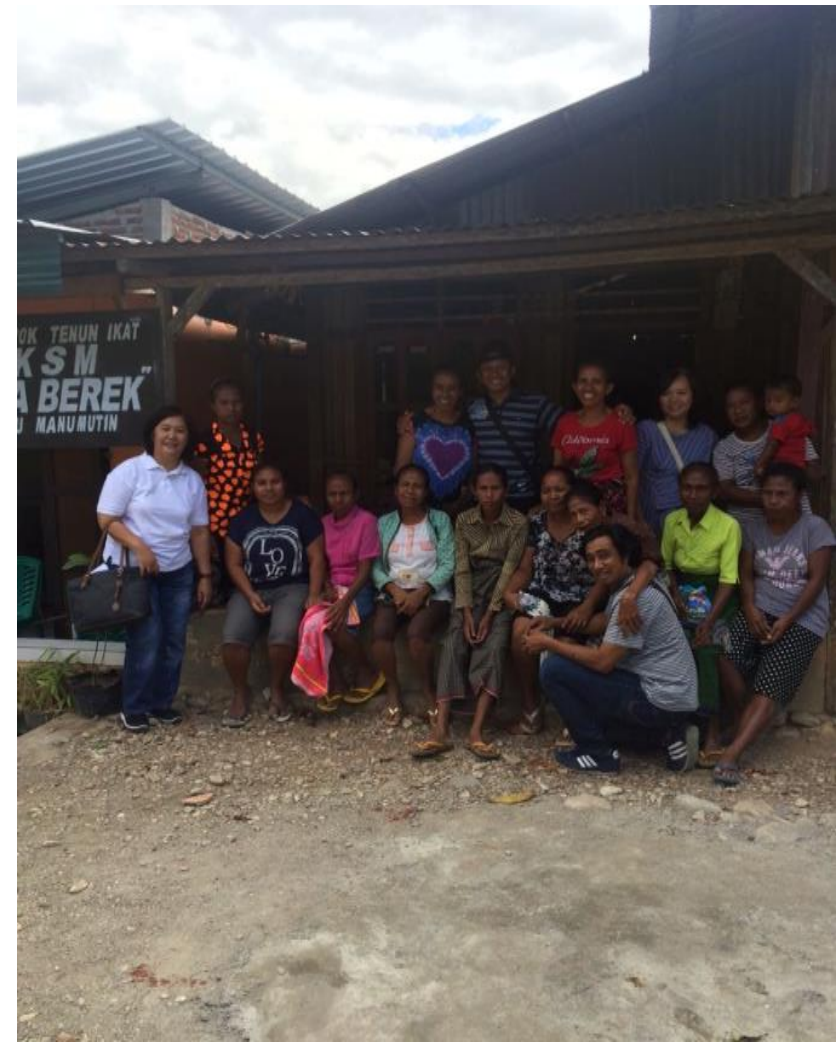

Gambar 1. Foto Kegiatan (1)

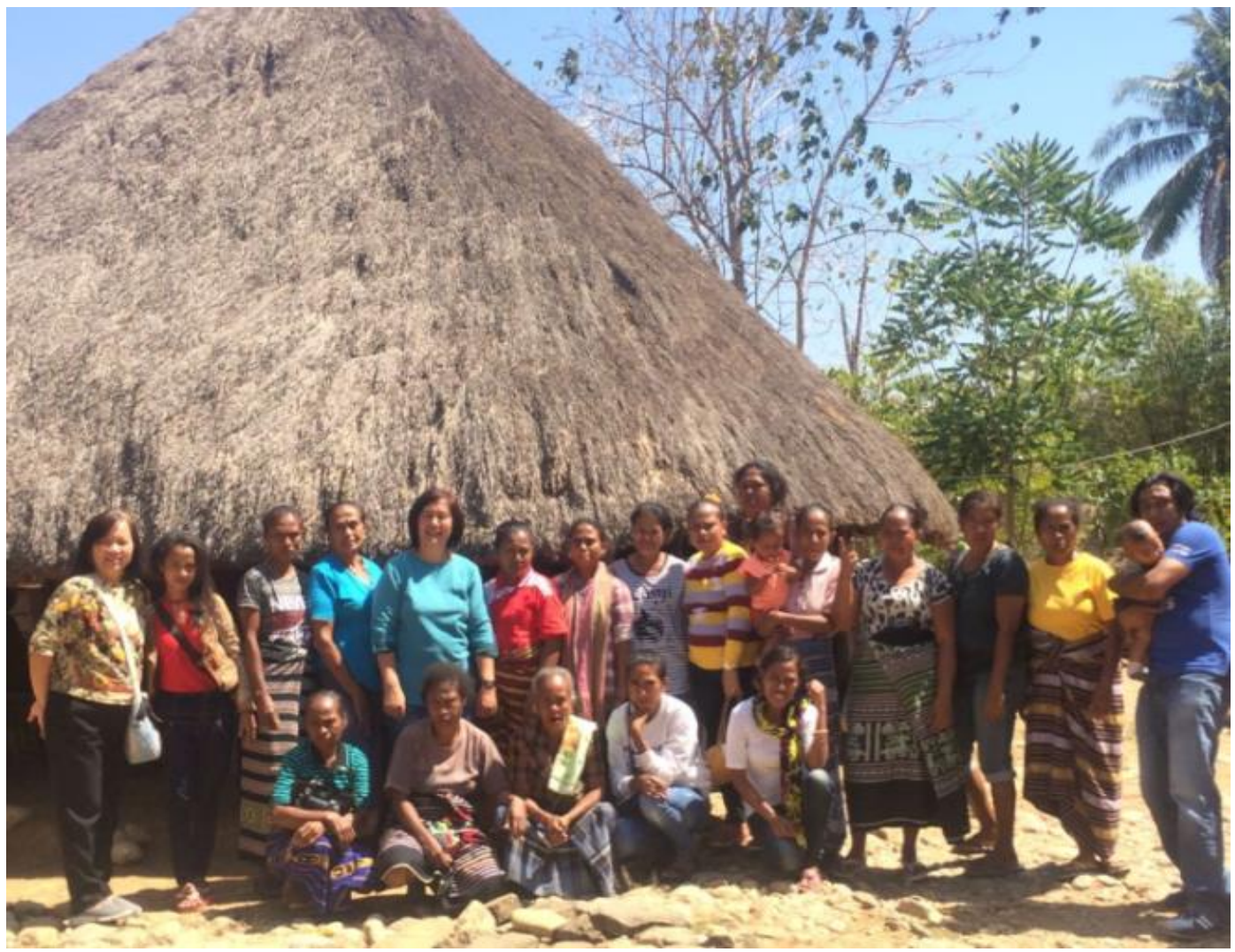

Gambar 2. Foto Kegiatan (2) 


\section{REFERENSI}

Fallo, K. (2016). Bertenun, cara tepat dongkrak pendapatan anggota kelompok Bia Berek di Atambua. Diambil 6 September 2019, dari http://www.sesawi.net/bertenun-cara-tepatdongkrak-pendapatan-anggota-kelompok-bia-berek-di-atambua/

Rangnekar, D. (2003). Geographical indications: A review proposal at the TRIPS council: Extending article 23 to products other than wines and spirits (p.4). Switzerland: International Centre for Trade and Sustanaible Development \& United Nations Conference on Trade and Development. Diambil dari https://unctad.org/en/PublicationsLibrary/ictsd2003ipd4_en.pdf

Saidin, O.K. (2004). Aspek hukum hak kekayaan intelektual (Cetakan ke-4). PT Raja Grafindo Perkasa.

Sinaga, S. (2012). Utilisation of intellectual property rights by Indonesian small medium enterprises: A case study of challenges facing Batik and Jamu industries (unpublished doctoral dissertation). University of Wollongong, Wollongong, Australia.

Sinaga, V. S. (2014) Faktor-Faktor Faktor-Faktor Penyebab Rendahnya Penggunaan Hak Kekayaan Intelektual di Kalangan Usaha Kecil Menengah Batik. Jurnal Hukum Ius Quia Iustum, 21 (1), 61-80. https://doi.org/10.20885/iustum.vol21.iss1.art4

The Trade Related Aspects of Intellectual Property Rights (TRIPS)

UU No. 28/ 2014 tentang Hak Cipta

UU No. 20/ 2016 tentang Merek dan Indikasi Geografis

UU No. 30/ 2000 tentang Rahasia Dagang

UU No. 31/ 2000 tentang Desain Industri 